\title{
Management of Patients with Overactive Bladder in Brazil: A Retrospective Observational Study Using Data From the Brazilian Public Health System
}

\author{
Greta Lozano-Ortega (D) - Daniel B. Ng • Shelagh M. Szabo (D) · \\ Alison M. Deighton - Bruno Riveros • Anne Guttschow • \\ Katherine L. Gooch • Cristiano M. Gomes (D)
}

Received: October 28, 2019 / Published online: April 15, 2020

(C) The Author(s) 2020

\begin{abstract}
Introduction: In Brazil, current data on the use of healthcare resources to manage individuals with overactive bladder $(\mathrm{OAB})$ are lacking. This study aimed to characterize contemporary treatment and the economic burden among patients with $\mathrm{OAB}$ managed under the Brazilian public health system (Sistema Único de Saúde [SUS]).

Methods: Population-based data from January to December of 2015 were acquired from Brazil's
\end{abstract}

Digital Features To view digital features for this article go to https://doi.org/10.6084/m9.figshare.12026232.

Electronic Supplementary Material The online version of this article (https://doi.org/10.1007/s12325020-01318-w) contains supplementary material, which is available to authorized users.

G. Lozano-Ortega · S. M. Szabo · A. M. Deighton Broadstreet Health Economics and Outcomes Research, Vancouver, BC, Canada

D. B. Ng ( $₫)$ · A. Guttschow · K. L. Gooch Astellas Pharma Global Development, Inc., Northbrook, IL, USA

e-mail: daniel.ng@astellas.com

B. Riveros

MAPESolutions, Sao Paulo, Brazil

C. M. Gomes

Division of Urology, Department of Surgery, University of Sao Paulo-Sao Paulo/SP School of Medicine, Sao Paulo, Brazil public health database. Adults at least 18 years of age with an ICD-10 diagnostic code for OAB within the period were included. Records of outpatient visits, hospitalizations, and onabotulinumtoxinA injections were used to calculate estimates of resource use and costs (in Brazilian reals $[\mathrm{R} \$]$ ) among those with $\mathrm{OAB}$ (frequency [\%] and mean (standard deviation $[\mathrm{SD}]$ ) as appropriate). Patient identifiers were not available, so a record linkage methodology was used to match medical encounters to individuals. Pharmacologic management of OAB was informed by government medication purchases available from the official Brazilian government databases.

Results: During 2015, 26,640 patients with $\mathrm{OAB}$ were identified. All cohort members had at least one outpatient visit and 15,349 (57.6\%) were hospitalized. Of the study cohort, $10.0 \%$ visited a general practitioner (GP), 41.3\% visited a specialist, and $52.0 \%$ visited other non-medical healthcare practitioners within the year. Mean (SD) healthcare costs among the study cohort totaled $\mathrm{R} \$ 355(\mathrm{R} \$ 866)$ per patient per year; and were $\mathrm{R} \$ 291$ ( $\mathrm{R} \$ 654), \mathrm{R} \$ 27(\mathrm{R} \$ 130)$, $\mathrm{R} \$ 27$ ( $\mathrm{R} \$ 30)$, and $\mathrm{R} \$ 11$ ( $\mathrm{R} \$ 17$ ) for hospitalizations, GP, specialist, and non-medical healthcare practitioner visits per patient per year, respectively. Regional analysis of reported government medication purchases suggested that access to $\mathrm{OAB}$ treatments is highly limited.

Conclusions: High resource use and costs were estimated among patients with $\mathrm{OAB}$ managed 
within the SUS. These data provide a snapshot of the management of patients with $\mathrm{OAB}$ in Brazil, with the patients seeking treatment under SUS likely representing a more burdened subpopulation.

Keywords: Brazil public healthcare; Economic burden; Overactive bladder; Patient management; Urology

\section{Key Summary Points}

\section{Why carry out this study?}

An accurate understanding of the economic burden of overactive bladder $(\mathrm{OAB})$ requires knowledge of both disease prevalence and contemporary management practices.

While some studies of the prevalence of $\mathrm{OAB}$ in Brazil exist, studies exploring treatment practices and economic burden in relation to $\mathrm{OAB}$ are lacking.

This study sought to characterize contemporary treatment and the economic burden associated with the management of patients with $\mathrm{OAB}$ in the Brazilian public health system.

\section{What was learned from the study?}

This study helped highlight the undertreatment of $\mathrm{OAB}$ within the Brazilian public health system, and helped quantify healthcare resource use and associated costs among those actively managed for $\mathrm{OAB}$ within that system.

\section{INTRODUCTION}

Overactive bladder $(\mathrm{OAB})$ is a condition characterized by urinary urgency, with or without urinary incontinence, usually with nocturia, and urinary frequency [1]. Globally, estimates of $\mathrm{OAB}$ prevalence are widely variable, ranging between $11.8 \%$ and $30 \%$ of the adult population, with higher prevalence among older adults [2-4]. Because prevalence increases with age, and the proportion of people surviving into older age is growing, $\mathrm{OAB}$ is becoming an increasing burden on the healthcare system and providers [5]. In order to plan for that burden, accurate data on $\mathrm{OAB}$ prevalence and the healthcare resources used to manage individuals with $\mathrm{OAB}$ are needed.

In Brazil, estimates of the prevalence of $\mathrm{OAB}$ range from $7.6 \%$ to $25 \%$ [6-8]. The most contemporary of these estimates comes from a large population-based initiative that measured the frequency of lower urinary tract symptoms (LUTS) among patients aged 40 years and older. The prevalence of $\mathrm{OAB}$ in this study was estimated at approximately $25 \%$ (24\%, women; $25 \%$, men) [8].

An accurate understanding of the economic burden of $\mathrm{OAB}$ requires knowledge of both disease prevalence and contemporary management practices. Internationally, a 2005 study calculated total direct medical and nursing home costs among OAB sufferers in Canada, Germany, Italy, Sweden, Spain, and the UK to be in excess of 7 billion euro per year [9]. These costs are likely underestimates of the total potential burden, as while the majority of adults living with $\mathrm{OAB}$ may report their symptoms to a medical professional, a recent European study found that only $27 \%$ of individuals living with $\mathrm{OAB}$ seek pharmacologic treatment [10]. Presently, there are no published data on the economic burden of OAB in Brazil; however, given the size of Brazil's population, and the known prevalence of $\mathrm{OAB}$, the economic burden is likely substantial.

Because of a lack of comprehensive studies focusing on the pharmacologic treatment and costs of OAB in Brazil, many unanswered questions remain about the epidemiologic and health economic burden it poses. The overarching aim of this study was to characterize contemporary pharmacologic treatment and the economic burden associated with the management of patients with $\mathrm{OAB}$, from the perspective of the Brazilian public health system. 


\section{METHODS}

\section{Study Design and Patient Population}

This population-based retrospective cohort study focused on individuals who access care through the Brazilian public health system (Sistema Único de Saúde [SUS]), which provides healthcare for approximately 70\% of the country's population [11]. Beneficiaries who were 18 years of age or older and had a diagnosis indicative of $\mathrm{OAB}$ between January and December 2015 (referred to hereafter as the OAB cohort) were included. A prevalence-based approach was used because limited longitudinal data were available through which to identify newly diagnosed $\mathrm{OAB}$ cases. The $\mathrm{OAB}$ cohort was identified on the basis of the presence of medical encounters associated with one or more OAB-related International Classification of Diseases (ICD)-10 diagnostic codes (used within the Brazilian public health database) on inpatient or outpatient visits during the study period. As only 4-character ICD-10 codes were available in the Brazilian public health database (O Departamento de Informática do Sistema Único de Saúde, DATASUS), previously published lists of 5-digit ICD-9 codes for OAB [12-15] were mapped to corresponding 4-character ICD-10 codes (N32.8, Other specified disorders of the bladder; N39.4, Other specified urinary incontinence; R35.0, Frequency of micturition, R35.1 Nocturia, R39.1 Other difficulties with micturition, R39.8 Other symptoms and signs involving the genitourinary system) for identification of the cohort. All OAB codes were confirmed with clinical experts.

\section{Data Sources}

This study was conducted with populationbased data from DATASUS which includes hospital data collected by the SUS Hospital Information System (Sistema de Informações Hospitalares, SIH), and outpatient data collected by the Outpatient Information System (Sistema de Informações Ambulatoriais, SIA) [16-20]. Cost data (included as fields within the SIH and SIA datasets) provided by SUS are based on set fees established by the government and paid to public health providers.

Data were available for de-identified medical encounters in the public health system comprising outpatient visits and hospitalizations. For outpatient visits, these data included the type of practitioner visited and associated costs. Within DATASUS, healthcare practitioners are categorized as general practitioner (GP), specialist, and non-medical healthcare providers (the database does not provide details on the type of practitioner, but it would include physiotherapy and similar types of services). Hospitalizations were identified by an $O A B$ diagnostic code. Each hospitalization can have several diagnostic codes attributed to it; the presence of an $\mathrm{OAB}$ code is not necessarily indicative of the cause for the hospitalization. In the data it was indicated whether the patient had been admitted to the emergency room (ER), the intensive care unit (ICU), or a general ward; details on the length of stay, procedure undertaken, and associated costs were also available.

Each patient record includes information on the patient's state of residence, sex, and age group, as well as diagnostic code(s) [21]; note, unique patient identifiers to link records across different healthcare providers are not available in DATASUS. Therefore, a deterministic approach to linking was undertaken within and between the hospital (SIH) and outpatient (SIA) datasets to link medical encounters with recorded OAB-related ICD-10 codes to individuals [22]. Pseudo-identification numbers were generated by merging all available demographic characteristics from the two datasets (zip code, sex, and age for SIH, and city, sex, and age for SIA).

As dispensation information is only available at the class level within DATASUS, available data proved insufficient to characterize the pharmacologic management of $\mathrm{OAB}$ within the public healthcare system. Instead, during the study period, local, state and federal government purchases of medications which are almost exclusively for the treatment of $\mathrm{OAB}$ (e.g., darifenacin, oxybutynin, solifenacin, tolterodine, and onabotulinumtoxinA) were analyzed at the level of the region, where available, using information obtained from two 
government databases: the Sistema Integrado de Administração de Serviços Gerais (SIASG) and Banco de Preços em Saúde (BPS) databases $[23,24]$. These data were used to characterize uptake of $\mathrm{OAB}$ medications in Brazil within the public health system.

\section{Outcomes for Analysis}

The economic burden associated with the management of patients with $\mathrm{OAB}$ was characterized by mean (standard deviation [SD]) estimates of healthcare resource use and costs. Parameters summarized included the frequency of GP, specialist, and non-medical healthcare practitioner outpatient visits and associated costs; number of hospitalizations and associated costs; duration of hospital stays; number of hospital visits with codes for onabotulinumtoxinA injections to the bladder and associated costs; and use of pharmaceuticals for OAB management. It should be noted that presently, onabotulinumtoxinA is not eligible for reimbursement for OAB within SUS in Brazil; however, patients may access onabotulinumtoxinA in the private system, at the individual hospital level, and in rare cases through legal action. Costs for hospitalizations, onabotulinumtoxinA injections, and outpatient visits were presented as means (SD) per patient, as well as aggregated to estimate a cost for all medical services recorded among those with $\mathrm{OAB}$ for the entire cohort. Overall mean total costs were also calculated by age category. Unless otherwise stated, costs are presented in 2017 Brazilian reals (indicated as R\$); one US dollar (US\$) was approximately 3.49 Brazilian reals at the time of analysis [25]. Given the study objectives, all analyses were descriptive in nature.

DATASUS is under public domain; as such, approval from an ethics committee was not required [26]. Similarly, no ethics approval was necessary for accessing SIASG and BPS datasets. The study was conducted in accordance with STROBE guidelines for cohort studies.

\section{RESULTS}

\section{Cohort Identification and Characteristics}

A total of 26,640 individuals were identified as having sought medical attention for their $\mathrm{OAB}$ within the Brazilian public health system (SUS) in 2015. On the basis of an estimated adult population of 104 million included in DATASUS, this indicates that approximately $0.026 \%$ of the Brazilian population covered by SUS were managed for $\mathrm{OAB}$ within the public healthcare system in 2015. Seventy-two percent of the OAB cohort was female, and the mean age was 55.6 (SD 16.9) years (Table 1). The majority of the cohort was resident in the southeast region $(52.1 \%)$, followed by the northeast (18.4\%) (Table 1).

\section{Healthcare Resource Use and Costs}

Healthcare resource use and costs among the $\mathrm{OAB}$ cohort are reported in Table 2. All the patients in the cohort had a record of at least

Table 1 Demographic characteristics of the individuals of the OAB cohort $(n=26,640), 2015$

\begin{tabular}{lll}
\hline & \multicolumn{1}{l}{$\boldsymbol{N = \mathbf { 2 6 , 6 4 0 }}$} \\
\cline { 2 - 3 } & $\boldsymbol{n}$ & $\mathbf{\%}$ \\
\hline Sex: $n(\%)$ & 7471 & 28.0 \\
Male & 19,169 & 72.0 \\
Female & & \\
Region: $n$ (\%) & 814 & 3.1 \\
North & 4894 & 18.4 \\
Northeast & 2261 & 8.5 \\
Central west & 13,885 & 52.1 \\
Southeast & 4786 & 18.0 \\
South & Mean (SD) & Median (IQR) \\
& $55.6(16.9)$ & $56.0(24.0)$ \\
Age & &
\end{tabular}


Table 2 Healthcare resource use and costs among the OAB cohort $(n=26,640), 2015$

\begin{tabular}{|c|c|c|}
\hline & \multicolumn{2}{|c|}{ Resource use } \\
\hline & $\bar{n}$ & $\%$ \\
\hline Hospitalizations $^{a}$ & 15,349 & 57.6 \\
\hline \multicolumn{3}{|l|}{$n$ (\%) hospitalized, by hospital ward ${ }^{\mathrm{b}}$} \\
\hline ER & 165 & 0.6 \\
\hline ICU & 253 & 0.9 \\
\hline \multirow[t]{2}{*}{ General ward } & 15,183 & 57.0 \\
\hline & Mean & $(\mathrm{SD})$ \\
\hline $\begin{array}{l}\text { Among those hospitalized, mean (SD) } \\
\text { length of stay (days), by hospital ward }\end{array}$ & 3.4 & 4.8 \\
\hline ER & 1.1 & 1.2 \\
\hline ICU & 12.1 & 12.1 \\
\hline \multirow[t]{2}{*}{ General ward } & 3.3 & 4.5 \\
\hline & $n$ & $\%$ \\
\hline $\begin{array}{l}n(\%) \text { experiencing one or more } \\
\text { outpatient visits }\end{array}$ & 26,640 & 100.0 \\
\hline GP & 2664 & 10.0 \\
\hline Specialist & 10,994 & 41.3 \\
\hline \multirow[t]{3}{*}{ Other } & 13,845 & 52.0 \\
\hline & \multicolumn{2}{|c|}{ Costs $(\mathrm{R} \$)$} \\
\hline & Mean & SD \\
\hline Overall cost per patient per year & $\$ 355$ & $\$ 866$ \\
\hline $\begin{array}{l}\text { Overall hospitalization costs (patient/ } \\
\text { year) }\end{array}$ & $\$ 291$ & $\$ 654$ \\
\hline GP (mean cost/patient/year) & $\$ 27$ & $\$ 130$ \\
\hline Specialist (mean cost/patient/year) & $\$ 27$ & $\$ 30$ \\
\hline Other (mean cost/patient/year) & $\$ 11$ & $\$ 17$ \\
\hline $\begin{array}{l}\text { Hospitalizations (mean cost/hospital } \\
\text { stay) }\end{array}$ & $\$ 572$ & $\$ 1272$ \\
\hline ER (mean cost/hospitalization in ER) & $\$ 53$ & $\$ 28$ \\
\hline $\begin{array}{l}\text { ICU (mean cost/hospitalization in } \\
\text { ICU) }\end{array}$ & $\$ 7154$ & $\$ 6878$ \\
\hline
\end{tabular}

Table 2 continued

\begin{tabular}{|c|c|c|}
\hline & \multicolumn{2}{|c|}{ Resource use } \\
\hline & $n$ & $\%$ \\
\hline $\begin{array}{l}\text { General ward (mean cost/ } \\
\text { hospitalization in general ward) }\end{array}$ & $\$ 468$ & $\$ 384$ \\
\hline \multicolumn{3}{|c|}{$\begin{array}{l}\$ \text { Brazilian real, } E R \text { emergency room, } G P \text { General practi- } \\
\text { tioner, } I C U \text { intensive care unit, } S D \text { standard deviation } \\
\text { a } \% \text { corresponds to the absolute number of patients hos- } \\
\text { pitalized at least once compared to the total number of } \\
\text { patients } \\
\text { b \% of absolute number of patients admitted in specified } \\
\text { hospital ward at least once compared to the total number } \\
\text { of individuals in the OAB cohort }\end{array}$} \\
\hline
\end{tabular}

one outpatient visit in $2015 ; 10.0 \%(n=2664)$ visited a GP, $41.3 \%(n=10,994)$ visited a specialist, and $52.0 \%(n=13,845)$ visited a nonmedical healthcare provider. The mean (SD) cost per patient per year was $\mathrm{R} \$ 27$ ( $\mathrm{R} \$ 130)$ for GP visits, R\$27 (R\$30) for specialist visits, and $\mathrm{R} \$ 11$ (R\$17) for visits to other non-medical healthcare providers. Overall, mean total costs increased with increasing age; from a mean total cost of $\mathrm{R} \$ 103.70$ among those aged 25-35 years to $\mathrm{R} \$ 323.56$ among those aged 55-64 to $\mathrm{R} \$ 954.00$ among those aged 75 years or older (Fig. S1 in the supplementary material).

Over half of the cohort experienced one or more hospitalizations where one of the diagnosis codes, in any position assigned, was for OAB during $2015(n=15,349 ; 57.6 \%)$. The majority were seen in the general ward $(n=15,183 ; 57.0 \%)$ and their average (SD) length of stay was 3.3 days (4.5). Only 253 $(0.9 \%)$ patients had a record of an ICU admission, and $165(0.6 \%)$ patients were recorded as having been admitted to the ER. Among those with records of an ICU admission, the average (SD) length of stay was 12.1 days (12.1); among those with an ER admission it was 1.1 day (1.2). For those with recorded hospital visits, 175 (1.1\%) individuals were identified as having received treatment with onabotulinumtoxinA with a mean cost of $\mathrm{R} \$ 525 \quad(\mathrm{R} \$ 211)$ per 
Table 3 Brazilian government purchases of pills for the treatment of OAB in 2015

\begin{tabular}{lllllll}
\hline & \multirow{2}{*}{ Brazil } & \multicolumn{2}{l}{ By Region } & & \\
\cline { 3 - 7 } & & North & Northeast & Central west & Southeast & South \\
\hline Total number of pills & $4,316,920$ & 0 & $3,071,320$ & 966,649 & 268,820 & 10,131 \\
Darifenacin 7.5 mg & 3500 & 0 & 0 & 0 & 0 & 3500 \\
Oxybutynin 10 mg & 720 & 0 & 0 & 720 & 0 & 0 \\
Oxybutynin 5 mg & $4,302,820$ & 0 & $3,071,320$ & 963,649 & 263,420 & 4431 \\
Solifenacin 10 mg & 1200 & 0 & 0 & 0 & 0 & 1200 \\
Solifenacin 5 mg & 3000 & 0 & 0 & 0 & 3000 & 0 \\
Tolterodine 4 mg & 5680 & 0 & 0 & 2280 & 2400 & 1000 \\
\hline
\end{tabular}

treatment (data not shown). The mean (SD) cost per patient per year for hospital stays was R \$291 (R\$654). Mean (SD) cost per hospitalization on individual wards was $\mathrm{R} \$ 468(\mathrm{R} \$ 384)$ for the general ward, $\mathrm{R} \$ 7,154(\mathrm{R} \$ 6,878)$ for the ICU, and $\mathrm{R} \$ 53(\mathrm{R} \$ 28)$ for the ER.

Overall costs for medical services among those with $\mathrm{OAB}$ during the study period totaled $\mathrm{R} \$ 355$ (R\$866) (US\$102 [US\$248]) per patient per year and amounted to $\mathrm{R} \$ 9,457,200$ (US\$2,709,799) across the study cohort [25].

\section{Pharmacologic Management}

In $2015,4,316,920$ pills of medications primarily used for the management of OAB were purchased by the Brazilian government. Of these, $99.7 \%$ were oxybutynin, primarily in a $5 \mathrm{mg}$ formulation $(4,316,920$ pills purchased), with a negligible amount in a $10 \mathrm{mg}$ formulation (720 pills purchased). It was estimated that the number of oxybutynin pills purchased nationwide in 2015 (Table 3) would cover a full year of treatment at the recommended $15 \mathrm{mg}$ dose per day for about 4000 individuals.

On a regional level, the majority of the reported purchases were made in the northeast region of Brazil (71.1\%), followed by the central west (22.4\%; Fig. 1; Table 3$)$. A very low proportion of the purchases were for the southeast $(6.2 \%)$ and south $(0.2 \%)$ regions. No purchases were recorded in the north region of Brazil
(Table 4). It should be noted that 12 states had no pharmacologic $\mathrm{OAB}$ treatments listed on their formularies and 11 others had no data available on medication purchases.

\section{DISCUSSION}

Estimates of the economic burden of $\mathrm{OAB}$ in Brazil are presently lacking. This study has used a population-based dataset comprising data from the Brazilian public health service to identify a cohort with $\mathrm{OAB}$ in Brazil in order to investigate healthcare resource use and costs. Estimates were established for outpatient and inpatient resource use nationally and for publicsector OAB-related medication purchases at a regional level. These estimates are valuable because of their use for planning purposes. In addition, they provide insight into the limited access to medication for $\mathrm{OAB}$ through the public health service across many regions of the country. Almost 27,000 individuals had medical encounters within the public healthcare system in 2015 where OAB-related symptoms were addressed. Within this cohort, resource use was high, with $57.6 \%$ of patients experiencing hospitalizations and outpatient visits being frequent. Costs of management of these patients were estimated at almost 10 million reals in 2015. Data on the purchases of OAB medications made by the Brazilian government 


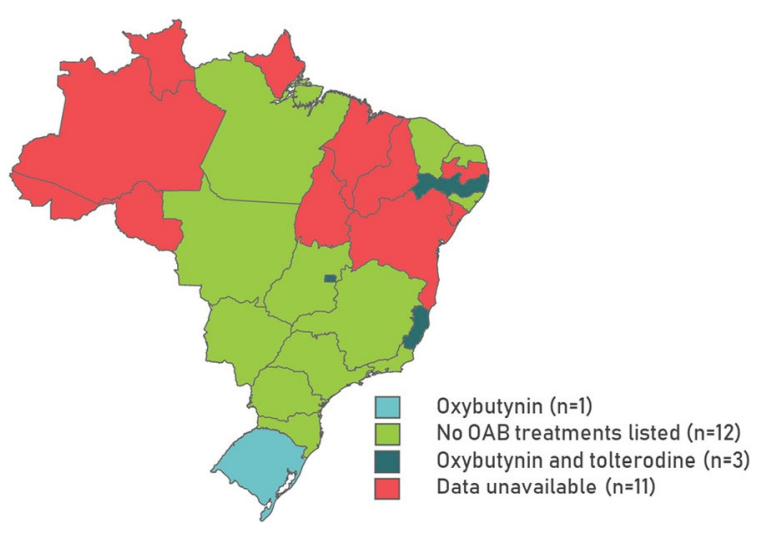

Fig. $1 \mathrm{OAB}$ treatments listed on formularies by Brazilian state, 2015. Map by Free Vector Maps (https:// freevectormaps.com). $O A B$ overactive bladder

indicated limited access to pharmacologic $\mathrm{OAB}$ treatments in some regions of the country.

Two studies of self-reported $\mathrm{OAB}$ in Brazil have estimated prevalence to be between $18.9 \%$ [6] and 25\% [8], using an adapted version of the King's Health Questionnaire and the OAB-V8, respectively. While establishing $\mathrm{OAB}$ prevalence was not feasible from this study, it should be noted that these numbers stand in sharp contrast to the estimated $0.026 \%$ of the Brazilian population covered by SUS that had medical encounters associated with $\mathrm{OAB}$ (as indicated by the presence of an ICD-10 code for OAB-related symptoms) within the public healthcare system in 2015. As OAB is largely understood to be an underdiagnosed condition $[29,30]$, and case identification via ICD codes would require an individual to seek medical care, prevalence estimates based on self-reported symptoms are generally higher than those based on ICD codes alone $[2,31]$. There are a number of reasons for this: (1) the misconception that symptoms are a normal part of aging and therefore not reported to physicians [5, 32]; (2) embarrassment around discussing OAB symptoms with their doctor [5], which prevents cases from being identified and noted in medical records; (3) when OAB is discussed with a doctor, it may be mentioned with more burdensome comorbidities, to which the visit is coded, as there is no obligation to record secondary diagnoses. It is also possible that Brazilians are aware of the regional variability in access to $\mathrm{OAB}$ treatments (as indicated by the present study), or that the public health system will not provide care [32] and therefore do not seek pharmacotherapy. A recent study exploring barriers to access to healthcare in Brazil noted that patients accessing care through the public health service cited a lack of availability of health centers, doctors, and drugs, as well as longer waiting times [33]. An investigation of

Table 4 Uptake of OAB medications by region based on government purchases, 2015

\begin{tabular}{lllllll}
\hline & \multirow{2}{*}{ Brazil } & By region & & & \\
\cline { 3 - 7 } & & North & North east & Central west & Southeast & South \\
\hline Percent of total purchases (\%) & & 0.0 & 71.1 & 22.4 & 6.2 & 0.2 \\
Darifenacin & 0.1 & 0.0 & 0.0 & 0.0 & 0.0 & 0.1 \\
Oxybutynin & 99.7 & 0.0 & 71.1 & 22.3 & 6.1 & 0.1 \\
Solifenacin & 0.1 & 0.0 & 0.0 & 0.0 & 0.1 & 0.0 \\
Tolterodine & 0.1 & 0.0 & 0.0 & 0.1 & 0.1 & 0.0 \\
Population estimate & $207,848,000^{\mathrm{a}}$ & $17,251,384$ & $57,781,744$ & $15,380,752$ & $87,504,008$ & $29,930,112$ \\
Population percent $(\%)^{\mathrm{b}}$ & & 8.3 & 27.8 & 7.4 & 42.1 & 14.4 \\
\hline
\end{tabular}

Regional population estimates were calculated on the basis of regional distribution percentages from the 2010 Census, multiplied by the WHO overall population estimate from 2015

a Source: Global Health Observatory [27]

b Source: IBGE (Brazilian Institute of Geography and Statistics) [28] 
patient perceptions of the availability of $\mathrm{OAB}$ pharmacotherapies in different regions of Brazil could inform this hypothesis.

Even given these considerations, the number of patients identified through DATASUS was lower than expected. In their study of $\mathrm{OAB}$ prevalence, Teloken et al. [6] explored the proportion of patients accessing treatment; of the 160 who sought medical counselling for their $\mathrm{OAB}$, only 30 received pharmaceutical treatment (types of treatment were not specified). This rate is higher than recent data from the USA where only $8.1 \%$ of patients with OAB were reported to be receiving treatment [30]. Using this figure as a broad estimate with the more conservative prevalence estimate (18.9\%), it was initially expected that the cohort identified from DATASUS would represent about $1.5 \%$ of those covered by SUS, rather than the $0.026 \%$ observed. Two possible explanations for that are (1) in Teloken et al.'s study [6], most patients surveyed who acknowledged seeking treatment for $\mathrm{OAB}$ were not in the public health systemwhich denotes a worrisome imbalance and undertreatment of those in the public health system; and, (2) OAB is undercoded within DATASUS (particularly given that there has been low specificity in the ICD codes used for identifying actual $\mathrm{OAB}$ cases). Considering these suspected contributing factors, this cohort of individuals identified within DATASUS may represent a subpopulation of patients with urinary symptoms indicative of $\mathrm{OAB}$ with burdensome comorbid conditions who expressed a felt need for healthcare [34]. This hypothesis is supported by the fact that only $20 \%$ of identified hospitalization records had an OAB-related ICD code in the 1st or 2 nd position (i.e., as primary or secondary diagnosis).

This study has shed light on the limited access and the regional disparities in access to $\mathrm{OAB}$ medication through the public sector healthcare service. Oxybutynin accounts for virtually all purchases of medicines specific to the treatment of $\mathrm{OAB}$ within the Brazilian public health service, potentially due to it being the most economical [35]. Regionally, in the Southeast, the country's most populous region, only the state of Espirito Santo had OAB medications (oxybutynin and tolterodine) listed on its formulary, and its population represents only $4.5 \%$ [28] of the total population of the region. While we do not have private sector data for comparison, due to the lack of availability of pharmacologic $\mathrm{OAB}$ therapies within SUS, it is clear that the number of patients with $\mathrm{OAB}$ accessing care through the public sector is low and it is conceivable, as a result, that only a small subset of patients with OAB actively seek management of their condition through SUS.

To the best of the authors' knowledge, the present study is the first to present an estimate of the economic burden of OAB to the Brazilian public healthcare system. The lack of granularity in the available data has meant that we are unable to attribute costs presented here directly to $\mathrm{OAB}$ (i.e. the costs presented are not OABspecific) though an OAB-related code was present in each case. The data available was also limited in that it does not permit the direct matching of patients to encounters, which precluded the presentation of all-cause costs. As such, the figures presented here are characterized as costs associated with the management of patients with $\mathrm{OAB}$, and despite the aforementioned limitations we do believe they can assist in characterizing the burden of $\mathrm{OAB}$ in Brazil.

Among the OAB cohort identified from SUS in 2015, the mean length of hospital stay was 3.3 days and the mean (SD) hospitalization cost was $\mathrm{R} \$ 572$ (R\$1,272). No Brazilian publications were identified that reported on inpatient stays within an $\mathrm{OAB}$ population against which to contrast the findings of this study. However, the costs that resulted from the underlying lengths of stay were similar to values reported for other conditions in Brazil, where the mean cost per hospitalization has ranged from $\mathrm{R} \$ 503$ to $\mathrm{R} \$ 566$ $[26,36]$. Although the mean hospitalization cost per patient in the present study was comparable to other published estimates, it is important to note that as the costs provided by SUS are based on set fees established by the government and paid to public health providers, the actual amount spent by the service provider is likely higher [26].

Another important finding of this study was the limited access to in-hospital procedural interventions for the management of OAB (e.g., onabotulinumtoxinA, percutaneous tibial nerve 
stimulation, and sacral neuromodulation). As it turns out, none of these procedures are available in Brazil within the public healthcare system, although a minority of individuals are granted special access to onabotulinumtoxinA; as such, it was not surprising that a small number of onabotulinumtoxinA injections into the bladder were identified in the data.

A key strength of this study was its population-based approach. The results provide insight into the current management of OAB in Brazil, in particular providing estimates of resource use and costs associated with the management of $\mathrm{OAB}$ which, to the best of the authors' knowledge, are presently lacking in the literature. A wide range of healthcare resources and costs were considered in the study, including both inpatient and outpatient use as well as medication uptake. The wide variety of data sources drawn on for the study, which enabled the formation of a comprehensive picture of the management and healthcare resource use associated with the management of OAB in Brazil, also add to the study's strengths.

There are several limitations that warrant mentioning. Firstly the unavailability of 5-digit ICD-10 codes through which to identify OAB cases required a mapping of the validated list of 5-digit codes specific to $\mathrm{OAB}$, to broader 4-character codes. This may have led to misclassification of patients with other urinary tract conditions as having $\mathrm{OAB}$; leading to an inflation of the cohort size and inclusion of patients with other urinary conditions. However, it is important to note that misclassification was unavoidable, as there are no 4-digit codes indicative of $\mathrm{OAB}$. An a priori decision was made in favor of overestimation because at least that would lead to an upper threshold estimate of the economic burden of OAB to the public healthcare system. Underinclusion would have also led to an imprecise estimate that was deemed less useful. Misclassification may also have impacted specific estimates of resource use and costs, although the direction of this impact is unknown, as this would depend on the intensity of clinical management required by the other urinary health condition. Thirdly, availability of medication data only at the class level in DATASUS limited the ability to understand $\mathrm{OAB}$ prescribing patterns within the cohort. As anticholinergic medications, as a class, are prescribed for several conditions, it was not possible to identify antimuscarinic medications prescribed for OAB specifically. This limitation was addressed by accessing supplementary data sources that report on drug purchases across Brazilian states, which provided a picture of medication access in this country. It should be noted, however, that as data were unavailable for a number of states, the estimates reported by region may represent a lower bound of medication uptake in each region. Additionally, the unavailability of patient identifiers with DATASUS required the generation of pseudo identification codes. Within the outpatient data, only sex, age, and city were available for linkage. The combination of these fields did not provide enough granularity for a linkage in the full general population dataset, so the linkage relied on medical encounters with OAB-related codes to increase the likelihood of success of the linkage protocol. This feature of the data led to the following study limitations: (a) inability to capture nonOAB-related resource use and costs, so that resource use and costs were only captured for encounters coded with an OAB-related ICD code; (b) inability to explore the degree to which $\mathrm{OAB}$ was responsible for the OAB-related hospital encounters identified; and (c) inability to identify a comparison cohort without OAB. Thus, individual-level estimates of resource use and costs identified here may not be relevant to all individuals with $\mathrm{OAB}$ in Brazil, particularly for those not actively seeking treatment. Finally, as administrative claims databases are developed for billing rather than research purposes, the results may be limited because of potential coding and data entry errors in the classification of diagnoses and procedures. And further, as the data for this study comprises medical events and medication purchases occurring within the Brazilian public health sector, the results may not be applicable to those accessing medical services either entirely or in a complementary manner through the private sector. 


\section{CONCLUSION}

This study provides new evidence on the management of $\mathrm{OAB}$ within the Brazilian public healthcare system, as well as healthcare resource use and costs among those actively seeking management of their OAB. Total 1-year healthcare costs incurred among those with suspected $\mathrm{OAB}$ were in excess of $\mathrm{R} \$ 9,457,200$; or $\mathrm{R} \$ 355$ per cohort member. This is despite what appears to be very limited access to OAB pharmacotherapies in Brazil for those covered under SUS, at present, and considering limited data access. Accurate estimation of $\mathrm{OAB}$ prevalence was not feasible using data from DATASUS. Nevertheless, the disparity between published prevalence estimates and the number of patients managing their $\mathrm{OAB}$ within the Brazilian public healthcare system in this study highlights a great unmet need for pharmacologic $\mathrm{OAB}$ treatment in Brazil within SUS. Future research is needed that focuses on the private healthcare system to better understand the overall economic burden of OAB in Brazil.

\section{ACKNOWLEDGEMENTS}

Funding. The present study was initiated by Astellas Pharma Global Development, Inc. Northbrook, IL, USA, and funding for the conduct of this study was provided by Astellas Pharma Global Development, Inc. Publication of the study results was not contingent on permission from the sponsor. The Rapid Service and Open Access Fees were funded by Astellas Pharma Global Development, Inc.

Medical Writing and Editorial Assistance. We would like to thank Elizabeth Badillo for drafting, reviewing and editing this manuscript. Elizabeth Badillo is an employee of Broadstreet HEOR, which received payment from Astellas for this assistance.

Authorship. All named authors meet the International Committee of Medical Journal Editors (ICMJE) criteria for authorship for this article, take responsibility for the integrity of the work as a whole, and have given their approval for this version to be published.

Disclosures. Daniel Ng and Anne Guttschow are employees of Astellas Pharma Global Development, Inc. Katherine Gooch was an employee of Astellas Pharma Global Development, Inc. and is now an employee of Sarepta Therapeutics, Cambridge, MA. Greta LozanoOrtega, Alison Deighton and Shelagh Szabo are employees of Broadstreet HEOR, which received payment from Astellas to conduct the study. Bruno Riveros received payment from Broadstreet HEOR for data access and analysis. Cristiano Gomes received payment from Astellas for consultation services in the conduct of this study.

Compliance with Ethics Guidelines. DATASUS is under public domain; as such, approval from an ethics committee was not required [26]. Similarly, no ethics approval was necessary for accessing SIASG and BPS datasets.

Data Availability. Researchers may request access to anonymized participant level data, trial level data and protocols from Astellas sponsored clinical trials at www. clinicalstudydatarequest.com. For the Astellas criteria on data sharing, see https:// clinicalstudydatarequest.com/Study-Sponsors/ Study-Sponsors-Astellas.aspx.

Open Access. This article is licensed under a Creative Commons Attribution-NonCommercial 4.0 International License, which permits any non-commercial use, sharing, adaptation, distribution and reproduction in any medium or format, as long as you give appropriate credit to the original author(s) and the source, provide a link to the Creative Commons licence, and indicate if changes were made. The images or other third party material in this article are included in the article's Creative Commons licence, unless indicated otherwise in a credit line to the material. If material is not included in the article's Creative Commons licence and your intended use is not permitted by statutory regulation or exceeds the permitted use, you 
will need to obtain permission directly from the copyright holder. To view a copy of this licence, visit http://creativecommons.org/licenses/by$\mathrm{nc} / 4.0 /$.

\section{REFERENCES}

1. Abrams P, Cardozo L, Fall M, et al. The standardisation of terminology in lower urinary tract function: report from the standardisation subcommittee of the International Continence Society. Urology. 2003;61(1):37-49.

2. Stewart W, Van Rooyen J, Cundiff G, et al. Prevalence and burden of overactive bladder in the United States. World J Urol. 2003;20(6):327-36. https://doi.org/10.1007/s00345-002-0301-4.

3. Coyne KS, Sexton CC, Bell JA, et al. The prevalence of lower urinary tract symptoms (LUTS) and overactive bladder $(\mathrm{OAB})$ by racial/ethnic group and age: results from OAB-POLL. Neurourol Urodyn. 2013;32(3):230-7. https://doi.org/10.1002/nau. 22295.

4. Irwin DE, Milsom I, Hunskaar S, et al. Populationbased survey of urinary incontinence, overactive bladder, and other lower urinary tract symptoms in five countries: results of the EPIC study. Eur Urol. 2006;50(6):1306-15. https://doi.org/10.1016/j. eururo.2006.09.019.

5. Milsom I, Stewart W, Thuroff J. The prevalence of overactive bladder. Am J Manag Care. 2000;6(11 Suppl):S565-S573573.

6. Teloken C, Caraver F, Weber FA, et al. Overactive bladder: prevalence and implications in Brazil. Eur Urol. 2006;49(6):1087-92.

7. Moreira ED Jr, Neves RCS, Neto AF, et al. A population-based survey of lower urinary tract symptoms (LUTS) and symptom-specific bother: results from the Brazilian LUTS epidemiology study (BLUES). World J Urol. 2013;31(6):1451-8. https:// doi.org/10.1007/s00345-013-1057-8.

8. Soler R, Gomes CM, Averbeck MA, Koyama M. The prevalence of lower urinary tract symptoms (LUTS) in Brazil: Results from the epidemiology of LUTS (Brazil LUTS) study. Neurourol Urodyn. 2017. https://doi.org/10.1002/nau.23446.

9. Milsom I, Coyne KS, Nicholson S, Kvasz M, Chen CI, Wein AJ. Global prevalence and economic burden of urgency urinary incontinence: a systematic review. Eur Urol. 2014;65(1):79-95. https://doi.org/ 10.1016/j.eururo.2013.08.031.
10. Milsom I, Abrams P, Cardozo L, Roberts RG, Thuroff $\mathrm{J}$, Wein AJ. How widespread are the symptoms of an overactive bladder and how are they managed? A population-based prevalence study. BJU Int. 2001;87(9):760-6.

11. Ministério da Saúde. $71 \%$ dos brasileiros têm os serviços públicos de saúde como referência 2015. https://www.brasil.gov.br/saude/2015/06/71-dosbrasileiros-tem-os-servicos-publicos-de-saudecomo-referencia. Accessed 3 Dec 2017.

12. Ng DB, Espinosa R, Johnson SJ, Walker D, Gooch K. The impact of persistence with mirabegron usage vs switching to onabotulinumtoxinA on healthcare costs and resource utilization in patients with overactive bladder in the United States. J Med Econ. 2017;20(12):1272-80. https://doi.org/10.1080/ 13696998.2017.1367300.

13. Chancellor MB, Migliaccio-Walle K, Bramley TJ, Chaudhari SL, Corbell C, Globe D. Long-term patterns of use and treatment failure with anticholinergic agents for overactive bladder. Clin Ther. 2013;35(11):1744-51. https://doi.org/10.1016/j. clinthera.2013.08.017.

14. Pelletier EM, Vats V, Clemens JQ. Pharmacotherapy adherence and costs versus nonpharmacologic management in overactive bladder. Am J Manag Care. 2009;15(4 Suppl):S108-S114114.

15. Yeaw J, Benner JS, Walt JG, Sian S, Smith DB. Comparing adherence and persistence across 6 chronic medication classes. J Manag Care Pharm. 2009;15(9):728-40. https://doi.org/10.18553/jmcp. 2009.15.9.728.

16. Bahia LR, Araujo DV, Schaan BD, et al. The costs of type 2 diabetes mellitus outpatient care in the Brazilian public health system. Value Health. 2011;14(5):S137-S140140.

17. Sartori AMC, Valentim J, Soárez PCd, Novaes HMD. Rotavirus morbidity and mortality in children in Brazil. Rev Panam Salud Publica. 2008;23(2): 92-100.

18. Tedesco-Silva H, Manfro RC, Asano E, et al. PUK7 immunosuppressant therapy patterns and its costs in post kidney transplant patients in the national transplant program in Brazil. Value Health. 2010;13(3):A77. https://doi.org/10.1016/S10983015(10)72362-7.

19. David-Neto E, Carvalho DBM, Carvalho F, et al. PUK21 post-kidney transplant morbidity related rehospitalizations in the Brazilian public health system: causes, resources use and costs based on an administrative registry review from 2004 to 2009 . Value Health. 2010;13(3):A80. https://doi.org/10. 1016/S1098-3015(10)72376-7. 
20. Duro-Garcia V, Abbud-Filho M, Esmeraldo RM, et al. PUK22 rejection episodes requiring hospitalization after kidney transplant in Brazil: a retrospective database study of the Brazilian public health system. Value Health. 2010;13(3):A80. https://doi.org/10.1016/S1098-3015(10)72377-9.

21. Leite Ida C, Valente JG, Schramm JMdA, et al. Burden of disease in Brazil and its regions, 2008. Cad Saude Publica. 2015;31(7):1551-64.

22. Dusetzina SB, Tyree S, Meyer AM, Meyer A, Green L, Carpenter WR. Linking data for health services research: a framework and instructional guide. Rockville: Agency for Healthcare Research and Quality, 2014 Contract No.: AHRQ Publication No. 14-EHC033-EF.

23. Ministério da Saúde. Banco de Preços em Saúde 2017. https://portalsaude.saude.gov.br/index.php/ cidadao/principal/banco-de-precos-em-saude.

24. Ministério do Planejamento DeG. Sistema Integrado de Administração de Serviços Gerais 2017. https://www.comprasgovernamentais.gov.br/ index.php/comprasnet-siasg.

25. XE Currency Charts: USD to BRL 2018. https:// www.xe.com/currencycharts $/$ from $=U S D \&$ to $=$ BRL. Accessed 30 April 2018.

26. Cardoso TdA, Roncada C, Silva ERd, et al. The impact of asthma in Brazil: a longitudinal analysis of data from a Brazilian national database system. J Bras Pneumol. 2017;43(3):163-8.

27. Global Health Observatory. Countries, Brazil: World Health Organization; 2015. https://www. who.int/countries/bra/en/. Accessed 16 Apr 2018.

28. Instituto Brasileiro de Geografia (IBGE). 2010 Population statistics; 2010. https://ww2.ibge.gov.br/ english/estatistica/populacao/censo2010/default. shtm. Accessed 16 Apr 2018.

29. Macdiarmid SA. Maximizing the treatment of overactive bladder in the elderly. Rev Urol. 2008;10(1):6-13.
30. Benner JS, Becker R, Fanning K, et al. Bother related to bladder control and health care seeking behavior in adults in the United States. J Urol. 2009;181(6): 2591-8. https://doi.org/10.1016/j.juro.2009.02. 018.

31. Cisternas MG, Foreman AJ, Marshall TS, Runken MC, Kobashi KC, Seifeldin R. Estimating the prevalence and economic burden of overactive bladder among Medicare beneficiaries prior to Medicare Part D coverage. Curr Med Res Opin. 2009;25(4):911-9. https://doi.org/10.1185/ 03007990902791025.

32. Wennberg AL, Molander U, Fall M, Edlund C, Peeker R, Milsom I. Lower urinary tract symptoms: lack of change in prevalence and help-seeking behaviour in two population-based surveys of women in 1991 and 2007. BJU Int. 2009;104(7):954-9. https:// doi.org/10.1111/j.1464-410X.2009.08534.x.

33. Garcia-Subirats I, Vargas I, Mogollon-Perez AS, et al. Barriers in access to healthcare in countries with different health systems. A cross-sectional study in municipalities of central Colombia and north-eastern Brazil. Soc Sci Med. 2014;106:204-13. https:// doi.org/10.1016/j.socscimed.2014.01.054.

34. Perry S, Shaw C, Assassa P, et al. An epidemiological study to establish the prevalence of urinary symptoms and felt need in the community: the Leicestershire MRC Incontinence Study. Leicestershire MRC Incontinence Study Team. J Public Health Med. 2000;22(3):427-34.

35. Suguino RS, Martins G, Campos BCV, et al. Oxybutynin and tolterodine for treatment of neurogenic detrusor overactivity: a pharmacoeconomic evaluation in the Brazilian context. Brazil J Pharmaceut Sci. 2012;48(2):227-36. https://doi.org/10. 1590/S1984-82502012000200006.

36. Silveira REd, Santos ÁdS, Sousa MCd, Monteiro TSA. Expenses related to hospital admissions for the elderly in Brazil: perspectives of a decade. Einstein (São Paulo). 2013;11(4):514-20. 